\title{
Anterior Ischemic Optic Neuropathy After Combined Ophthalmic Artery Embolization and Craniofacial Surgery
}

-Case Report-

\author{
Mohammad JAmOUS, Koichi SATOH, Teruyoshi KAGEJI, Junichiro SATOMI, \\ Shunji MATSUBARA, Shinji NAGAHIRO, Masakazu HAYASHI, ${ }^{*}$ \\ and Shinichi NAKAGAWA**
}

Departments of Neurological Surgery, *Ophthalmology, and ** Otorhinolaryngology, School of Medicine, The University of Tokushima, Tokushima

\begin{abstract}
A 57-year-old man developed visual loss following craniofacial surgery for an inflammatory ethmoidal sinus mass. Surgery was preceded by endovascular occlusion of the ophthalmic artery distal to central retinal artery (CRA). Routine angiography obtained immediately after endovascular ophthalmic artery occlusion showed patency of the CRA. He complained of visual loss one day after craniofacial surgery (2 days after embolization). Repeat emergency angiography confirmed the patent CRA. Ophthalmic examination and fluorescein angiography showed that the visual loss was due to anterior ischemic optic neuropathy (AION). Preservation of the CRA is critical during ophthalmic artery embolization to avoid visual complications. Neurosurgeons should be aware of the possibility of AION as a complication of ophthalmic artery embolization.
\end{abstract}

Key words: anterior ischemic optic neuropathy, ophthalmic artery embolization, platinum coil, fluorescein angiography, posterior ciliary artery

\section{Introduction}

Anterior ischemic optic neuropathy (AION) is a disease of old age, characterized by sudden, painless, and usually irreversible loss of vision. The cause is most likely to be impaired perfusion within the microcirculation of the optic nerve head, resulting in ischemic injury. Several systemic factors may be involved in the pathogenesis of AION, but the underlying cause(s) remain unclear. The ophthalmic artery provides the main blood supply to the orbital structures and ocular apparatus, so embolization of this vessel is not without risk, and visual loss is a known complication of ophthalmic artery embolization for various cranial lesions. Central retinal artery (CRA) occlusion due to migration of the embolic material is thought to be implicated in the occurrence of visual loss. We report a rare case of AION resulting in visual loss after craniofacial surgical resection of a nasal lesion preceded by ophthalmic artery embolization.

Received March 5, 2001; Accepted May 16, 2001

\section{Case Report}

A 57-year-old man had a 20-year history of recurrent nasal bleeding that was managed by compression and nasal packing. Cranial magnetic resonance (MR) imaging obtained in January 1997 showed a left ethmoidal sinus mass. Surgical excision was attempted in February 1997. However, the procedure was stopped after massive uncontrollable bleeding from the lesion. The biopsy specimen showed nonspecific rhinitis. The patient had another bleeding episode in August 1998. Embolization was thought to be the best therapy to reduce the vascularity of the lesion. Preoperative MR imaging showed an isointense mass on $\mathrm{T}_{1^{-}}$and $\mathrm{T}_{2}$-weighted images (Fig. 1). Digital subtraction angiography (DSA) confirmed the high vascularity of the lesion, showing a mass stain originating at the ethmoidal branches of left ophthalmic artery and left internal maxillary artery (Fig. 2).

Embolization of the ophthalmic artery was planned to interrupt the blood supply to the deep portion of the lesion. We decided not to embolize the facial and internal maxillary arteries to avoid com- 

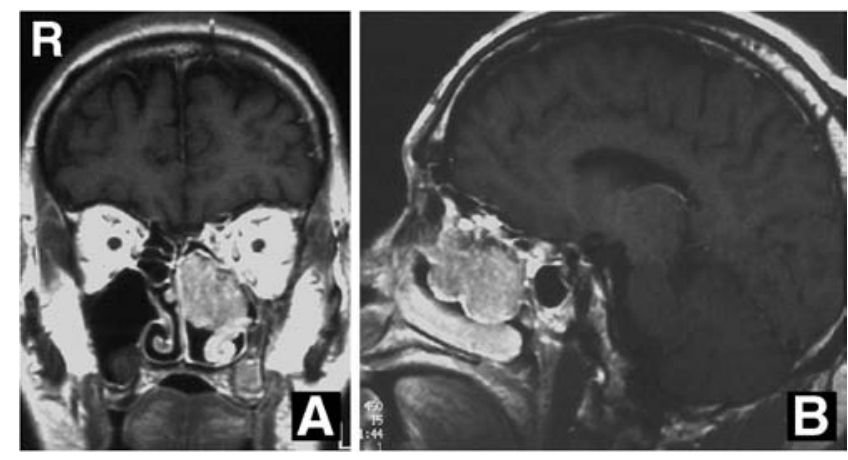

Fig. 1 Coronal (A) and sagittal (B) $T_{1}$-weighted magnetic resonance images with gadolinium showing the left nasal lesion extending to the left ethmoidal sinus.
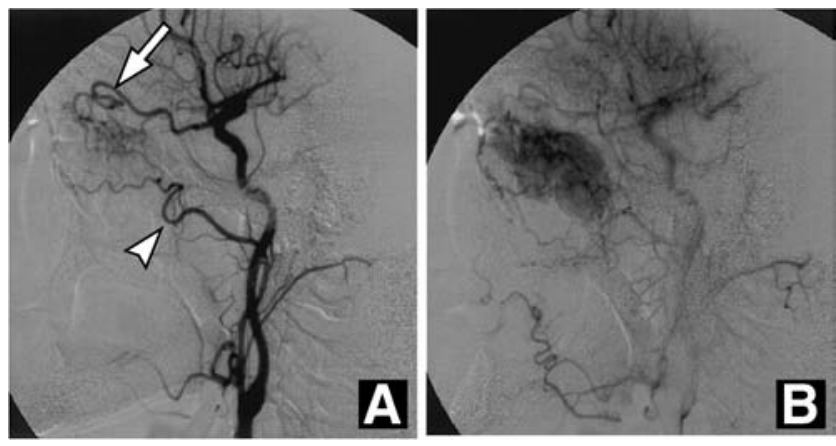

Fig. 2 Arterial (A) and capillary phase (B) left carotid angiograms showing the left ophthalmic (arrow) and left internal maxillary arteries (arrowhead) supplying the lesion. Note the mass stain.

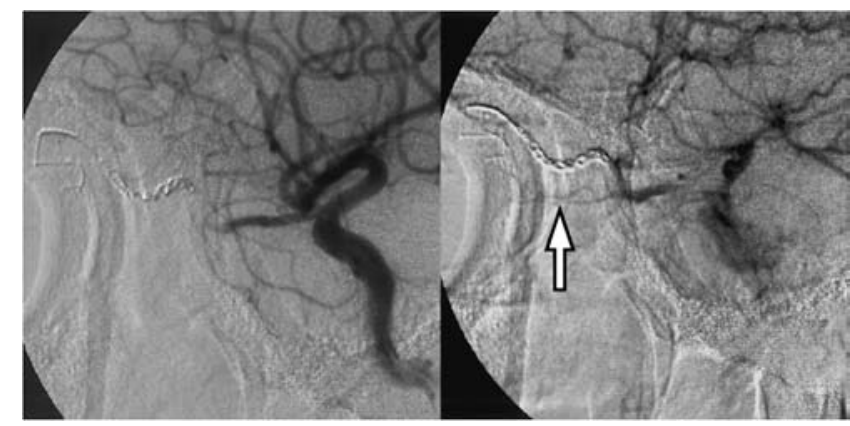

Fig. 3 Left internal carotid angiograms after endovascular coil occlusion of the distal part of the left ophthalmic artery. The left central retinal artery is preserved (arrow). Note that the mass stain at the left ophthalmic artery has disappeared.

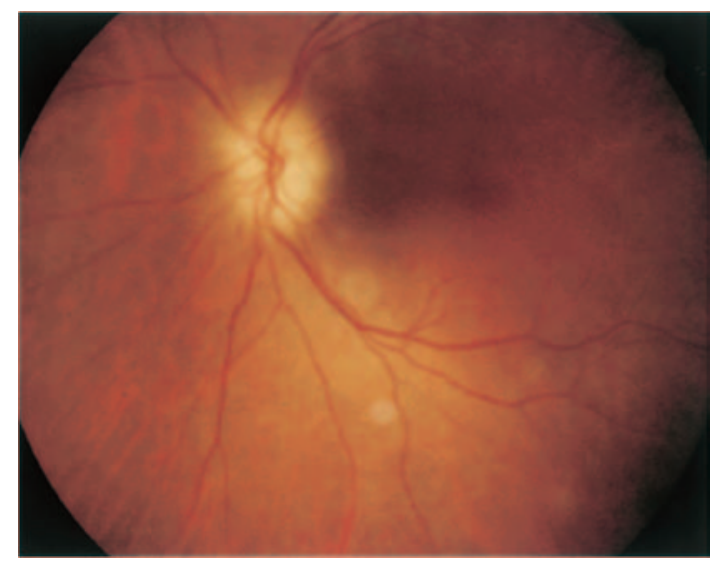

Fig. 4 Postoperative image of the left fundus showing optic disc edema and the normal central retinal artery.

plications with wound healing following craniofacial surgery. Coils were chosen as the embolizing material, because we feared that powder or liquid materials might migrate to the CRA and surrounding structures. A Fas Tracker-10 system was inserted into the ophthalmic artery and a 2-mm long fibered platinum coil (Target Therapeutics, Fremont, Calif., U.S.A.) used to occlude the ophthalmic artery distal to the CRA. DSA after embolization showed the preserved CRA and the choroidal crescent (Fig. 3). The patient did not receive anti-platelet therapy following the procedure to minimize the risk of bleeding during surgery.

Surgery was performed the day after embolization via bifrontal craniotomy using the transbasal and transfacial approach. The left ethmoidal sinus was opened through the left supraorbital bar and the rostral portion of the lesion was removed transcranially. Endoscopy of the left naris was used to remove the caudal parts. The mass was totally removed with only minimal bleeding.

Immediate postoperative examination revealed no visual problems, but the patient complained of visual loss in the left eye at 24 hours after surgery. Ophthalmic examination revealed decreased visual acuity and swollen left optic disc (Fig. 4). There were no findings suggestive of traumatic uveitis, retinal detachment, or traumatic optic neuropathy. Urgent DSA obtained on the same day showed that the CRA was intact (Fig. 5). Fluorescein angiography revealed a defect surrounding the optic disc and delayed filling in the same area (Fig. 6). The diagnosis was AION. Administration of high doses of steroids was ineffective. 


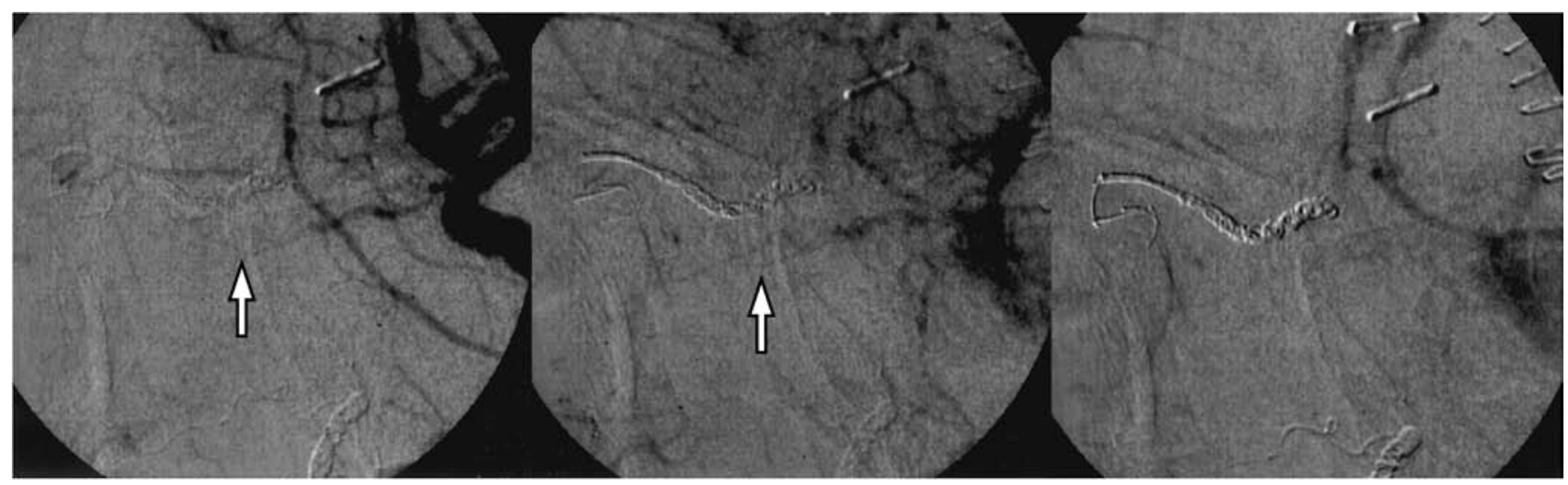

Fig. 5 Postoperative left carotid angiograms showing no coil migration and the patent central retinal artery (arrow).
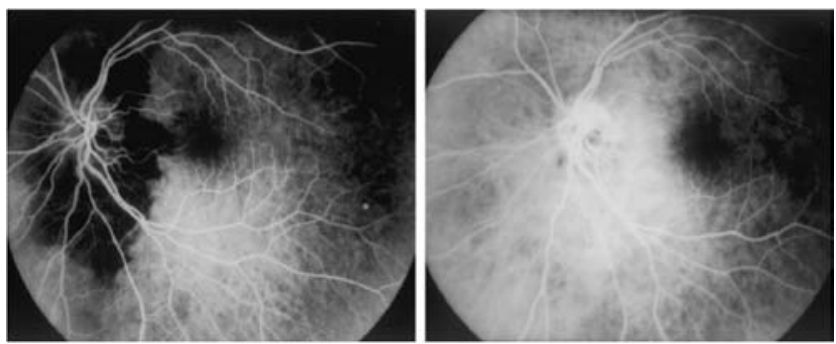

Fig. 6 Fluorescein angiograms of the left fundus showing a filling defect surrounding the optic disc in early phase (left, 18.7 seconds after contrast medium injection), and delayed filling in late phase (right, 41.1 seconds).

\section{Discussion}

AION is a microvascular disease resulting from occlusion of the short posterior ciliary arteries that provide the main blood supply to the optic head., ${ }^{2,14}$ The causes and associated conditions can be classified into three major groups: Arteritis (giant cell arteritis, polyarteritis nodosa, and systemic lupus); hematological causes (polycythemia vera, sickle cell disease, and glucose-6-phosphate dehydrogenase deficiency); and systemic vasculopathies (hypertension, diabetes mellitus, atherosclerosis, and carotid occlusive disease). Our patient has no history of arteritis or hematological disease, so we believe that a vascular disorder was responsible. The visual loss resulting from AION is usually sudden and discovered upon waking, suggesting that nocturnal hypotension is involved. ${ }^{14)}$ Ocular examination often reveals decreased visual acuity with various types of visual field defects, most commonly involving the lower part, a loss of afferent light reflex, and optic disc edema. ${ }^{6,8,12)}$ Fluorescein angiography is usually an excellent diagnostic tool, showing delayed filling of the optic head. ${ }^{2)}$ However, there is no effective treatment for AION at present. 3,7$)$

The blood supply to the orbit is primarily from the ophthalmic artery, which originates from the supraclinoid, the first major branch of the internal carotid artery. ${ }^{11)}$ The ophthalmic artery enters the orbit at the inferolateral aspect of the optic nerve. The intraorbital course of the ophthalmic artery is divided into three segments. The ocular branches (the CRA, posterior and anterior ciliary arteries) originate from the first and second intraorbital segments. The ophthalmic artery anastomoses with various branches of the external carotid artery, ensuring an adequate blood supply to the orbit and ocular apparatus even after internal carotid artery occlusion.9,11)

The ophthalmic artery may be involved in the vascularization of various cranial diseases. . $^{1,5,10,13,15,16)}$ Preoperative embolization is sometimes necessary and the risk of visual loss should always be considered when contemplating this procedure. Embolization must be distal to the second segment of the intraorbital part of the ophthalmic artery to avoid migration of the embolic material to the CRA. ${ }^{4,5,10,15)}$ Visual complications following ophthalmic artery embolization are common, and tend to be attributed to injury of the CRA. ${ }^{4,5,10,15)}$ However, we suggest that the procedure is the direct cause of visual complications in many patients with ophthalmic artery embolization. Migration of the embolic materials to the choroidal artery will not necessarily result in AION because the external carotid artery usually provides an adequate collateral blood flow. Consequently, AION may become apparent only after surgical interruption of the collateral flow to the 
choroidal circulation via the external carotid artery. Therefore, this rare complication may occur after combined ophthalmic artery embolization and craniofacial surgery. Our patient experienced visual loss although the CRA was preserved. Neurosurgeons should carefully consider the possibility of AION in patients scheduled for ophthalmic artery embolization and craniofacial surgery.

\section{References}

1) Alvarez H, Rodesch G, Garcia-Monaco R, Lasjaunias P: Embolisation of the ophthalmic artery branches distal to its visual supply. Surg Radiol Anat 12: 293-297, 1990

2) Arnold AC, Helper RS: Fluorescein angiography in acute NAION. Am J Ophthalmol 117: 222-230, 1994

3) Arnold AC, Helper RS: Natural history of nonarteritic anterior ischemic optic neuropathy. J Neuroophthalmol 14: 66-69, 1994

4) Castillo B Jr, De Alba F, Thornton J, De Brun G, Pulido J: Retinal artery occlusion following coil embolization of carotid-ophthalmic aneurysms. Arch Ophthalmol 118: 851-852, 2000

5) Goldberg RA, Garcia GH, Duckwiler GR: Combined embolization and surgical treatment of arteriovenous malformation of the orbit. Am J Ophthalmol 116: 17-25, 1993

6) Hayreh SS: Anterior ischemic optic neuropathy. V. Optic disc edema an early sign. Arch Ophthalmol 99: 1030-1040, 1981

7) Kelman S: Optic nerve decompression surgery for non-arteritic anterior ischemic optic neuropathy (NAION) is not effective and may be harmful. JAMA 273: 625-632, 1995
8) Kline LB: Progression of visual defects in ischemic optic neuropathy. Am J Ophthalmol 106: 199-203, 1988

9) Lasjaunias P, Vignaud J, Hasso AN: Maxillary artery blood supply to the orbit: normal and pathological aspect. Neuroradiology 9: 87-97, 1975

10) Matsumaru $Y$, Alveras $H$, Rodesch G, Lasjaunias PL: Embolisation of branches of the ophthalmic artery. Interventional Neuroradiology 3: 239-245, 1997

11) Newton TH, Mani RL: The ophthalmic artery, in Newton TH, Potts DG (eds): Radiology of the Skull and Brain, vol 2. St Louis, Mosby, 1974, pp 1333-1390

12) Repka MX, Savino PJ, Schatz NJ, Sergott RC: Clinical profile and long term implications of AION. Am J Ophthalmol 96: 478-483, 1983

13) Rootman J, Shine C, Kao S, Graeb DA: Multidisciplinary approaches to complicated vascular lesions of the orbit. Ophthalmology 99: 1440-1446, 1992

14) Simmons L: Nonarteritic anterior ischemic optic neuropathy. Arch Ophthalmol 117: 386-389, 1999

15) Terada T, Kinoshita Y, Yokote H, Tsuura M, Itakura T, Komai N, Nakamura Y, Tanaka S, Kuriyama T: Preoperative embolization of meningiomas fed by ophthalmic branch arteries. Surg Neurol 45: 161-166, 1996

16) Tsai FY, Wadley D, Angle JF, Alfieri K, Byars S: Superselective ophthalmic angiography for diagnostic and therapeutic use. AJNR Am J Neuroradiol 11: 1203-1204, 1990

Address reprint requests to: K. Satoh, M.D., Department of Neurological Surgery, School of Medicine, The University of Tokushima, 3-18-15 Kuramoto-cho, Tokushima 770-8503, Japan. 